\section{Retrospective analysis of endemic melasma patients}

\author{
Serkan Demirkan, ${ }^{1}$ Özgür Gündüz, ${ }^{1}$ \\ Cemile Dayangan Sayan ${ }^{2}$
}

${ }^{1}$ Department of Dermatology; and

${ }^{2}$ Department of Gynecology and

Obstetric, Kırkkale University,

Kırıkkale, Turkey

\begin{abstract}
Melasma is an acquired diffuse hypermelanosis characterized by localized, symmetrical, irregular, light-to-dark brown maculae occurring in sun-exposed areas of skin. The aim of this retrospective study was to determine demographics of patients, analysis of etiologic factors, clinical features, efficacy and side effects of available topical treatments due to high incidence of melasma patients. In this study melasma patients in Birecik State Hospital were investigated retrospectively. Between January 2014 and October 2015, 1008 patients had diagnosis of melasma in 49,809 applications of 24,603 different patients who admitted to Dermatology Outpatient Clinics. Of the 1008 patients, 263 had completed 3-month treatment period. These patients did not receive treatment in June, July, August and September. All melasma patients were rural and dealing with agriculture. There was no significant difference between female and male patients in terms of age. Of the 253 female melasma patients, only 2 of them had not child and none of them were using hormone drug. Of the 263 patients with melasma, Fitzpatrick skin type was 3 in $79(30 \%)$ patients, 4 in $184(70 \%)$ patients. Şanlıurfa city showed higher fertility rate, sun exposure, and skin type than Turkey as a whole. These predisposing factors may explain higher melasma occurrence in Şanliurfa. Patient information about preventive measures and treatment play important role in treatment of cosmetic condition. The most important measure seems to advise patients about sun-protection especially during pregnancy.
\end{abstract}

\section{Introduction}

Melasma is an acquired diffuse hypermelanosis characterized by localized, symmetrical, irregular, light-to-dark brown maculae occurring in sun-exposed areas of the skin. The condition mostly affects fertile women with skin types 4 to 6 according to

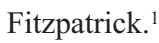

The etiology of melasma is multifactorial as it is affected by pregnancy, sun-exposure, hormone treatment, cosmetic use, and genetic predisposition. Most of the cases are due to sun exposure, pregnancy, and oral contraceptive use.

Persons of any race can be affected by melasma but is much more common in constitutionally darker skin types in comparison to lighter skin types i.e., it may be more common in light brown skin types, especially Latinos and Asians, from areas of the world with intense sun exposure. ${ }^{2}$

The pathophysiology of melasma is uncertain. A direct relationship with female hormonal activity appears to be present, because melasma occurs more frequently in females than in males and commonly develops or worsens during pregnancy as well as with the use of oral contraceptive pills. Indeed, one half of melasma cases present initially during pregnancy. Additionally, the expression of estrogen receptors appears to be up regulated in melasma lesions. Whether hormone levels play a role in male melasma development is still a topic of debate. Other factors implicated in the pathogenesis of melasma are photosensitizing medications, mild ovarian or thyroid dysfunction, and certain cosmetics.

The most important factor in the development of melasma is exposure to sunlight. Ultraviolet (UV) radiation is known to induce increased production of alphamelanocyte-stimulating hormone and corticotrophin, as well as interleukin 1 and endothelin 1, all of which contribute to increased melanin production by intraepidermal melanocytes. Fibroblasts located in the dermal layer of the skin may also contribute to the development of melasma; overexpression of the tyrosine kinase receptor c-kit and certain stem cell factors have been identified in melasma lesions, and these are believed to increase melanogenesis. ${ }^{3}$ Melasma is much more common in women than in men. Women are affected in $90 \%$ of cases. When men are affected, the clinical and histologic picture is identical.

Melasma is rare before puberty and most commonly occurs in women during their reproductive years. ${ }^{4}$

The macular hyperpigmentation of melasma is commonly tan to brown. Blue or black may be evident in patients with dermal melasma. The distribution is one of three patterns. Melasma may involve forehead, cheeks, nose, upper lip, chin. nose, cheek, and ramus of the mandible. ${ }^{4}$

Melasma Area and Severity Index (MASI) is commonly used for assessment of disease severity and response to treatment in melasma patients. MASI score is calculated according to affected skin area,
Correspondence: Serkan Demirkan, Department of Dermatology, Kırkkale University, Kırıkkale, Turkey.

Tel.: +90.(553).7717168.

E-mail: serkan.demirkan@yahoo.com.tr

Key words: Melasma, treatment; pregnancy; sun exposure; skin type.

Received for publication: 4 January 2017. Accepted for publication: 2 May 2017.

This work is licensed under a Creative Commons Attribution-NonCommercial 4.0 International License (CC BY-NC 4.0).

(C) Copyright S. Demirkan et al., 2017

Licensee PAGEPress, Italy

Dermatology Reports 2017; 9:7027

doi:10.4081/dr.2017.7027

darkness level of lesions, and homogeneity of hyperpigmentation. ${ }^{5}$

Therefore, it is important to raise awareness of patients about prevention strategies of this disease.

The aim of this retrospective study was to determine demographics of patients, analysis of etiologic factors, and clinical features due to the high incidence of melasma patients. Thus, in areas with high prevalence for melasma, the public can be informed about preventive methods and new strategies halting the development of melasma can be developed.

\section{Materials and Methods}

In this study melasma patients in Birecik State Hospital were investigated retrospectively. Due to the high incidence of melasma patients, patient information including personal details, treatment, skin type of patient, and patient satisfaction on electronic media were investigated. Using electronic data processing system named Fonet ${ }^{\circledR}$ Hbys in Şanlıurfa-Birecik State Hospital, we searched the patients who were recorded by ICD.10 code L81.1 which represents clinical melasma diagnosis. Between January 2014 and October 2015, 1008 patients had been diagnosed with melasma in 49,809 applications of 24,603 different patients who admitted to Dermatology Outpatient Clinics. Of the 1008 patients, 263 had completed a 3month treatment period. 745 patients did not return to control visits after they received their diagnosis and relevant treatment. Patients' skin types had been determined according to the Fitzpatrick classification. ${ }^{6}$

The full data of 263 patients were available which included skin-type, MASI score at first visit, irritation level and satisfaction 
level were evaluated retrospectively.

MASI is the most widely used outcome measure in clinical studies on melasma. ${ }^{7}$ MASI score, proposed by KimbroughGreen et al. in 1994, has been devised on the pattern of Psoriasis Area and Severity Index (PASI). ${ }^{8}$ MASI is primarily used in research and provides a quantitative index of the severity of melasma. Even though the MASI score is a objective measure, a recent study confirmed its reliability, stability, and consistency. ${ }^{5}$ Area of involvement (A): includes analysis of 4 areas including the forehead (f) $30 \%$; right malar region ( $\mathrm{rm}$ ) $30 \%$; left malar region $(\mathrm{lm}) 30 \%$; and the chin (c) $10 \%$. The area of melasma involvement is given a numeric value from 0 to 6 . Darkness (D): estimated and given a value from 0 to 4 . Homogeneity $(\mathrm{H})$ : estimated and given a value from 0 to 4 using the same scale as darkness. The MASI score is then calculated by the following formula: $0.3 \mathrm{~A}(\mathrm{f})[\mathrm{D}(\mathrm{f})+\mathrm{H}(\mathrm{f})]+0.3 \mathrm{~A}(\mathrm{rm})[\mathrm{D}(\mathrm{rm})+$ $\mathrm{H}(\mathrm{rm})]+0.3 \mathrm{~A}(\mathrm{~lm})[\mathrm{D}(\mathrm{lm})+\mathrm{H}(\mathrm{lm})]+0.1$ $\mathrm{A}(\mathrm{c})[\mathrm{D}(\mathrm{c})+\mathrm{H}(\mathrm{c})] \cdot{ }^{5}$ Patient's satisfaction and irritation levels were evaluated with visual analogue scale (VAS). VAS was first published in the early 1920 's $\mathrm{s}^{9,10}$ though not widely used at that time. ${ }^{11}$ The main advantage is that it takes only a few seconds to obtain a score, and imposes no inconvenience. ${ }^{11}$ VAS consists of the emotions that each person experiences as he/she points on a plane with a vertical line. Every emotion is judged according to the extent of experience i.e., the emotion is never experienced (e.g., I am not tense at all $=0$ ) otit is fully experienced (e.g., extremely tense $=100$ ). VAS assesses the following four emotional state categories: dysphoria, hostility, anxiety, and positive affect. ${ }^{12}$

Discomfort felt by patients with melasma; VAS was rated between 0 (no disturbance) and 10 (feeling of hostility). Accordingly, " 0 " indicates no feeling of disturbance; mean VAS value is $1-4$, dysphoria, 5-6 is anxiety, 7-10 is a feeling of hostility towards melasma.

Statistical analysis was made using SPSS ${ }^{\circledR} 21.0$ software package. Descriptive statistics were presented as mean \pm standard deviation. The statistical significance value was accepted as $\mathrm{P}<0.05$.

\section{Results}

It was observed that in 263 melasma patients did not receive treatment in June, July, August and September. All melasma patients were rural and dealing with agriculture. There was no significant difference between female and male patients in terms of age (Table 1). Of the 253 female melas- ma patients, only 2 of them had no child and none of them were using hormone drug. Of the 263 patients with melasma, the Fitzpatrick skin type 3 was seen in $79(30 \%)$ patients but the majority had the skin type 4 , i.e., $184(70 \%)$ patients. Male and female patients were comparable in terms of pretreatment MASI scores $(\mathrm{P}=0.15$ Mann Whitney U test) (Table 2). The patients had used four different treatment combinations.

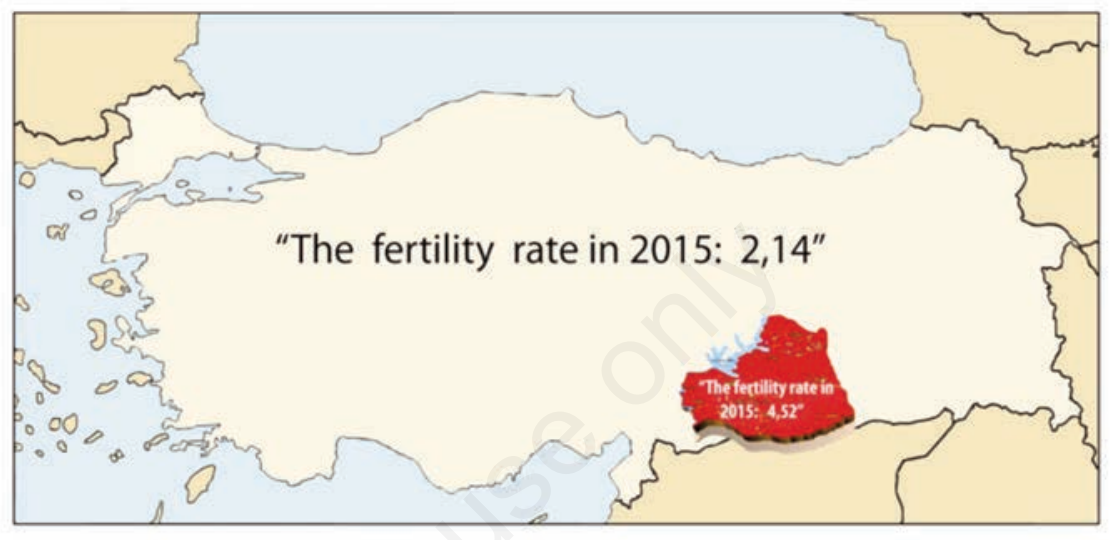

Figure 1. The fertility rate of Turkey and Şanlıurfa in 2015.

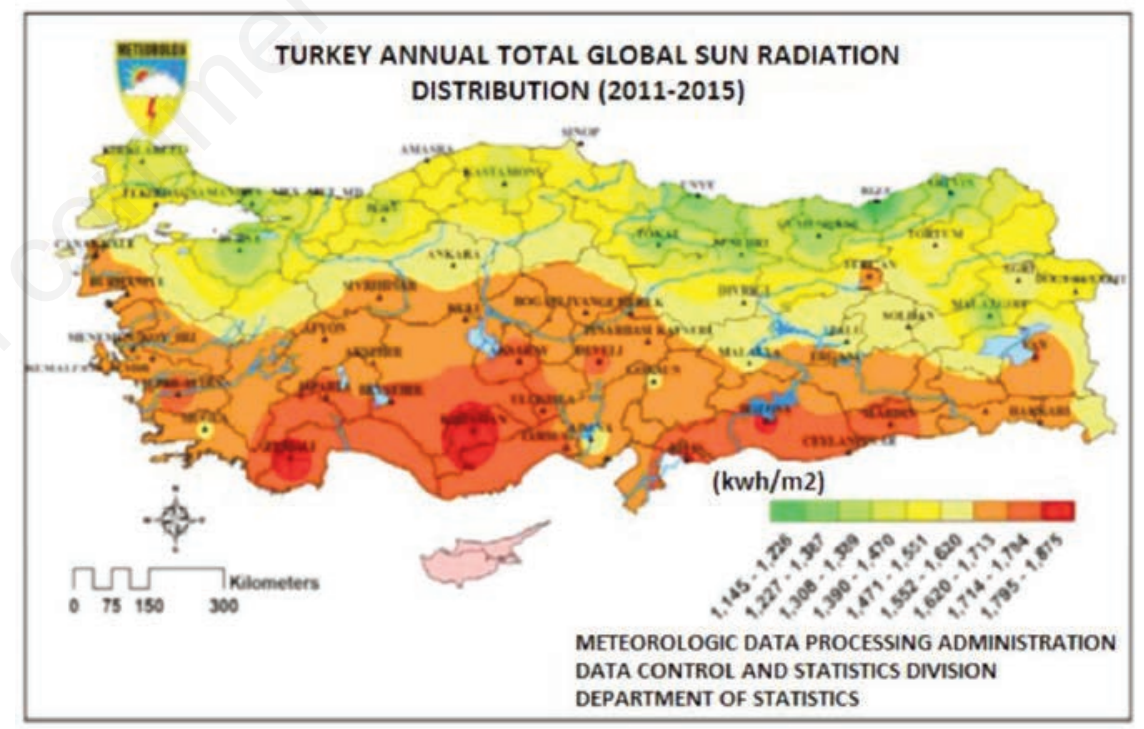

Figure 2. The average sun radiation between the years 2011-2015 in Turkey. ${ }^{19}$

Table 1. Descriptive features of male and female patients with melasma.

\begin{tabular}{|c|c|c|c|c|c|c|}
\hline & Number (\%) & & & Pre-t & ASI score & Average number of children \\
\hline Female & $253(96.8)$ & 27.9 & 27.93 & $12.50(5.5)$ & $12.66(5.4)$ & 3.89 \\
\hline Male & $10(3.2)$ & 30.0 & & $16.50(2.9)$ & & \\
\hline
\end{tabular}


Table 2. The correlation between MASI difference and patient's satisfaction and irritation.

\begin{tabular}{llcr} 
& MASI difference & $r^{* *}$ (Spearman correlation test) & $P$ \\
Patient's satisfaction & Correlation present & 0.380 & $<0.001$ \\
Irritation & Correlation present & 0.383 & $<0.001$ \\
\hline
\end{tabular}

Adapalene $0.1 \%+$ hydroquinone gel $4 \%$ $(\mathrm{N}=116)$; tretinoin $0.1 \%+$ hydroquinone gel $4 \%(\mathrm{~N}=71)$; azaleic acid $20 \%+$ hydroquinone gel $4 \%(\mathrm{~N}=48)$; tretinoin $0.05 \%+$ hydroquinone gel $4 \%(\mathrm{~N}=28)$.

The number of average children was correlated with the age of patients ( $\mathrm{r}$ : $0.443 * *, \mathrm{P}<0.001$, Spearman correlation test). There was no significant correlation between skin type of patients and pre-treatment MASI scores (r: $-0.055^{* *}, \mathrm{P}: 0.371$, Spearman correlation test).

\section{Discussion and Conclusions}

Melasma is an acquired diffuse hypermelanosis characterized by localized, symmetrical, irregular, light-to-dark brown maculae occurring in sun-exposed areas of skin. Considering these factors, the rate of pregnancy and sun-exposure data of Şanliurfa the city where study patients live are at risk of melasma.

It has been revealed that average number of children in female melasma patients was 3.89 which surpasses the average number of Turkey based on 2013, 2014, and 2015 figures reported by Turkish Statistics Administration, but it was comparable to fertility rate of Şanllurfa city. ${ }^{13}$ According to TÜIK data, the age group with the highest fertility rate in Turkey was in the age group of 25-29 between 2010-2015.In our study, female patients with melasma had a mean age of 27.9 years which is consistent with the former age group..$^{13}$ Total fertility rate is the average number of children that would be born to a women during her fertile period (15-49 years of age). In Turkey, total fertility rates for the years 2013, 2014 and 2015 were $2.10,2.18$, and 2.14 children, respectively. The highest total fertility rate was observed in Şanlıurfa in various cities of Turkey for the years 2013, 2014, and 2015 with $4.31,4.38$, and 4.52 children, respectively based on the data of Turkish Statistics Administration (TÜİK) (Figure 1). ${ }^{13}$

Muallem et al. and Moin et al. stated that pregnancy plays a role in the etiopathogenesis of melasma. As shown in our study, the fertility rate of our patients was above the rate of the general population in Turkey. ${ }^{14,15}$ Epidemiologic studies reported that more than one-fourth of the melasma patients had a history of excess sun-exposure. ${ }^{16-18}$ Figure 1 shows the average sun radiation between the years 2011-2015 in Turkey. ${ }^{19}$ Between the years 2011-2015, the average sun radiation for Turkey was around $1579 \mathrm{kwh} / \mathrm{m}^{2}$, whereas it is between 1714-1794 $\mathrm{kwh} / \mathrm{m}^{2}$ for Şanlıurfa. ${ }^{19}$ It is obvious that Şanliurfa is one of the cities with a higher fertility rate and a higher sun exposure (Figure 2). ${ }^{19}$

In a study conducted in Singapore, $90 \%$ of melasma patients had skin type 3 and $4 .{ }^{17}$ Similarly, in our study all patients had skin type 3 and 4. Cayce at al. reported that dermal type melasma is with worst response rate to treatment. In our study, we failed to find melasma classification data. ${ }^{20}$ Most of the studies investigated family history and suggested that this may have a role in etiology of melasma. However, in our study, we could not reach any information on family history of patients for melasma. Şanliurfa showed a higher fertility rate, sun exposure, and a different skin type than Turkey as a whole. These predisposing factors may explain higher melasma occurrence in Şanliurfa. Patient information about preventive measures and treatment play an important role in treatment of this cosmetic condition. The most important measure seems to advise patients about sun-protection especially during pregnancy.

\section{References}

1. Braun-Falco O, Plewig G, Wollff HH, Bugdorf WHC. Disorders of melaninpigmentation. In: Bischof $\mathrm{W}$, ed. Dermatology. 2nd ed. Berlin: SpringerVerlag; 2000. pp 1013-1043.

2. Sivayathorn A. Melasma in Orientals. Clin Drug Invest 1995;10:34-34.

3. Kang HY, Hwang JS, Lee JY, et al. The dermal stem cell factor and c-kit are overexpressed in melasma. Br J Dermatol 2006;154:1094-9.

4. Grimes PE. Melasma etiologic and therapeutic considerations. Arch Dermatol 1995;131:1453-7.

5. Tay EY, Gan EY, Tan VW, et al. Pilot study of an automated method to determine Melasma Area and Severity Index. BJD 2015;172:1535-40.

6. Fitzpatrick TB. "Soleil et peau" [Sun and skin]. J Méd Esthét 1975;2:33-4. [In French].

7. Jeong SY, Shin JB, Yeo UC, et al. Lowfluence Q-switched neodymium-doped yttrium aluminum garnet laser for melasma with pre- or post-treatment triple combination cream. Dermatol Surg 2010;36:909-18.

8. Kimbrough-Green CK, Griffiths CE, Finkel LJ, et al. Topical retinoic acid (tretinoin) for melasma in black patients. A vehicle-controlled clinical trial. Arch Dermatol 1994;130:727-33.

9. Hayes MHJ, Patterson DG. Experimental development of the graphic rating method. Psychol Bull 1921;18:98.

10. Freyd M. The graphic rating scale. J Educ Psych 1923;14:83-102.

11. Aitken RC. Measurement of feelings using visual analogue scales. P Roy Soc Med 1969;62:989-93.

12. Besser A, ve Priel B. Emotional responses to a romantic partner's imaginary rejection: The roles of attachmeny anxiet, covert narcissism, and self-evaluation. J Person 2009;77:287-325.

13. Turkish Statistics. [Türkiye İstatistik Kurumu, Doğum İstatistikleri, 2015]. Available from: http://www.tuik.gov.tr/ PreHaberBultenleri.do?id=21514 Accessed: June 24, 2016.

14. Muallem MM, Rubeiz NG. Physiological and biological skin changes in pregnancy. Clin Dermatol 2006;24:80.

15. Moin A, Jabery Z, Fallah N. Prevalence and awareness of melasma during pregnancy. Int J Dermatol 2006;45:285-88.

16. Achar A, Rathi SK. Melasma: a clinicoepidemiological study of 312 cases. Indian J Dermatol 2011;56:380-2.

17. Goh CL, Dlova CN. A retrospective study on the clinical presentation and treatment outcome of melasma in a tertiary dermatological referral centre in Singapore. Singapore Med J 1999;40: 455-8.

18. Tamega AA, Miot LD, Bonfietti C, et al. Clinical patterns and epidemiological characteristics of facial melasma in Brazilian women. J Eur Acad Dermatol Venereol 2013;27:151-6.

19. Turkish Statistics. [T.C ORMAN VE SU IŞLERI BAKANLIGI METEOROLOJI GENEL MUDURLUGU]. Available from: https://www.mgm.gov. tr/FILES/resmi-istatistikler/TurkiyeYillik-Günes-Radyasyonu.pdf Accessed: June 24, 2016.

20. Cayce KA, Feldman SR, McMichael AJ. Hyperpigmenation: a review of common treatment options. J Drugs Dermatol 2004;3:668-73. 